\title{
GUERREIROS RAMOS E A AUTOPOIESE: UM ANÚNCIO DO PARADIGMA SISTÊMICO
}

Mauro Gaglietti*

\section{RESUMO}

A teoria da autopoiese compartilha com a biocibernética os seguintes princípios: a) pensar sobre o pensar; b) aprender como se aprende; c) conhecer como se conhece. Apresentando traços desse novo paradigma, surgiu no Brasil, em 1981, a obra intitulada A nova ciência das organizações, de autoria de Guerreiro Ramos, negro, sociólogo e um dos expoentes da denominada inteligência brasileira. O livro propõe uma "reconceituação da riqueza das nações" - o que, por certo, consiste em uma crítica da teoria econômica de Adam Smith - por intermédio dos pressupostos organizacionais que postula. Guerreiro Ramos assinala, assim, que a ciência é compreendida como uma atividade que exige, sobretudo, equilíbrio entre razão e intuição. Nesses termos, ao propor um paradigma sistêmico, o sociólogo se integra a um movimento intelectual que contesta os fundamentos da ciência moderna e que, no campo jurídico, tem na obra de Luhmann e Teubner um referencial acerca da visão sistêmica no direito.

Palavras-chave: Autopoiese. Direito. Guerreiro Ramos. Luhmann. Paradigma sistêmico Teubner.

\section{INTRODUÇÃO}

Este trabalho situa a obra de Alberto Guerreiro Ramos intitulada $A$ nova ciência das organizações: uma reconceituação da riqueza das nações dentro da autopoiese, paradigma emergente que se relaciona à visão sistêmica da realidade, sobretudo se pudermos associá-lo às duas tendências contrárias de desenvolvimento do direito: de um lado, um processo progressivo de especialização formal, administrado de forma profissional e com incremento da sistematização interna; de outro, um processo em que o direito é exposto às exigências igualmente progressivas que o fazem incorporar elementos de justiça material, como conceitos de democratização e justiça social.

\section{A PERSPECTIVA SISTÊMICA NO DIREITO}

No campo do Direito, o paradigma sistêmico encontrou boa receptividade na medida em que a idéia de que o sistema legal constitui um sistema fechado não deve obscurecer o fato de que todo sistema mantém conexões com seu ambiente. Luhmann formula essa concepção da seguinte maneira: o sistema legal é aberto porque é fechado e é fechado porque é 
aberto. Esse paradoxo assinala a forma particular do relacionamento entre 0 sistema legal e o ambiente societário. O sistema legal, assim, tem seu componente e sua forma própria de expressão - a norma - e seu modo próprio de operação - o código lícito e ilícito. Pode ocorrer uma influência política na legislação, mas somente a lei pode modificar a lei. Somente dentro do sistema legal a mudança das normas legais pode ser percebida como mudança da lei (Luhmann, 1986, p. 113). O autor acrescenta, quanto a isso, que é sempre uma norma que decide quais fatos têm relevância legal ou não. Nesse sentido, 0 sistema jurídico é um sistema normativamente fechado. Ao mesmo tempo, esse sistema é cognitivamente aberto, o quer dizer que é estimulado pelas informações do ambiente. No caso específico do sistema legal, ele retira parte de sua dinâmica própria do processamento que realiza, segundo seu código, dos estímulos dos demais subsistemas sociais: político, econômico, educacional, moral etc. Na verdade, a fricção entre os subsistemas autoreferenciados e o ambiente é o que produz informação. Isso não seria possível, no entanto, se o sistema legal fosse apenas um sistema de normas e o ambiente fosse apenas cognição. Luhmann (1986, p. 114) enfatiza, então, que o sistema legal não é um sistema normativo no sentido de seus componentes serem os conteúdos das normas, ou no sentido ainda de determinarem o funcionamento do ambiente, mas sim um sistema de operações legais que usa sua auto-referência normativa para reproduzir a si próprio e para selecionar informações do meio.

O autor chama de dupla contingência dos sistemas o fato de eles operarem de maneira normativamente fechada, o que requer relações simétricas entre seus componentes, na medida em que um elemento dá sustentação ao outro e vice versa, e, ao mesmo tempo, operarem de maneira cognitivamente aberta, na qual a assimetria entre o sistema e seu ambiente os força a uma recíproca adaptação e mudança. Os sistemas legais apresentam uma maneira especial de resolver esse problema ao combinarem disposições normativas e cognitivas e estabelecerem condicionalidades para a introdução no sistema dos estímulos do ambiente. Nesse sentido, as normas legais, diferentemente das concepções de Kelsen e Durkheim, não derivam de uma ordem legal factual nem de uma norma fundamental, sendo, sim, "programas de condicionalidades" para a introdução no sistema de estímulos do ambiente (LUHMANN, 1986, p 115-119). O sistema legal, enfatiza o autor, não determina o conteúdo das decisões legais, nem logicamente tampouco por intermédio de procedimentos técnicos de uma hermenêutica jurídica. Ele opera como um sistema ao mesmo tempo fechado normativamente, o que garante sua manutenção e auto-reprodução, e aberto cognitivamente, no sentido de que está em contínua adaptação às exigências do ambiente.

Teubner, por sua vez, redimensiona o próprio conceito de autopoiese, desenvolvido por Maturana e Varela, assim como a definição dada por Luhmann, ao afirmar que esses autores trabalham com um conceito de autopoiese caracterizado, nas suas palavras, por uma rigidez inflexível, como um processo de tudo ou nada: o direito ou reproduz ou não reproduz a si próprio, não existindo algo como uma gradação no fenômeno da autopoiese. 0 autor afirma que um sistema se torna crescentemente auto-referencial quando a rede de seus componentes sofre modificações do seguinte tipo: maior 
feedback entre seus componentes, plasticidade funcional e plasticidade estrutural e constituição de novos componentes dentro da rede de componentes (TEUBNER, 1989, p. 67). Um sistema jurídico torna-se autônomo, afirma, na medida em que consegue constituir seus elementos ações, normas, processos, identidade - em ciclos auto-referenciais, só atingindo o termo pertinente de sua autonomia autopoiética quando os componentes do sistema, assim ciclicamente constituídos, se articulam entre si, formando um "hiperciclo" (TEUBNER, 1989, p. 58-67). Nesse sentido, a auto-referência e a autopoiese dão origem a um novo e mais elaborado tipo de autonomia do sistema jurídico em virtude da constituição de relações circulares, autonomia que, de modo algum, exclui a existência de interdependências causais entre o sistema jurídico e o sistema social (TEUBNER, 1989, p. 56). Essa espécie de autopoiese mitigada é analisada por Teubner a partir da distinção entre três elementos embutidos no processo de aumento cumulativo de relações circulares - o hiperciclo - e que fazem da autopoiese um processo gradativo: a auto-observação, a autoconstituição e a auto-reprodução. Segundo o autor,

uma coisa é um subsistema social observar os seus componentes (elementos, estruturas, processos, limites, identidade e meio envolvente) através de comunicação reflexiva (auto-observação); outra diferente é um sistema definir e colocar em operação por si só o conjunto dos componentes sistêmicos (autoconstituição); ainda uma outra coisa diferente é a capacidade de um sistema para se reproduzir a si mesmo através da produção (circular e recursiva) de novos elementos a partir de seus próprios elementos (autopoiesis). (TEUBNER, 1989, p. 68)

Percebe-se, assim, de uma maneira geral, que o grau de autonomia dos subsistemas sociais é determinado por uma escala crescente que parte da satisfação da primeira linha de exigências, ou seja, da definição autoreferencial de seus componentes, passa pela incorporação e utilização operativa do sistema dessa auto-observação e, finalmente, pela articulação hipercíclica dos componentes sistêmicos autoconstituídos. Para evitar qualquer confusão com alguma teleologia, Teubner se apressa em dizer que esses complexos hiperciclos que constituem os processos de autopoiese dos subsistemas sociais não evoluem de acordo com padrões predeterminados ou em direção à consecução de um fim particular. Nesse sentido, a chave para a compreensão da autonomia do sistema jurídico reside, segundo o autor, nessa relação tripartite de auto-observação, autoconstituição e auto-reprodução. Tão logo a comunicação jurídica sobre a distinção básica lícito/ilícito começa a diferenciar-se da comunicação social geral, ela se torna, inevitavelmente, autoreferencial e é compelida a tematizar a si mesma, tendo por referência as categorias intrinsecamente jurídicas. De uma maneira geral, esse é o processo que conduz à emergência de círculos auto-referenciais no que respeita a atos jurídicos, normas jurídicas, processos jurídicos e dogmática jurídica, o que, por sua vez, implica uma maior autonomia do sistema jurídico, o qual se torna perfeitamente auto-reprodutivo, afirma 0 autor, apenas quando seus componentes sistêmicos auto-referencialmente constituídos se encontram de tal modo imbricados que atos e normas jurídicas se produzem reciprocamente entre si e o processo jurídico e a doutrina jurídica relacionam, por seu turno, essas inter-relações (TEUBNER, 1989, p. 71). Em sentido estrito, portanto, a 
autonomia jurídica abrange não apenas a capacidade do direito de criar seus próprios princípios, mas também a capacidade de autoconstituição de ações, a juridificação dos processos e a criação de institutos "jurídico-doutrinais" (TEUBNER, 1989, p. 72).

Por fim, pode-se dizer que a análise sistêmica de Luhmann e Teubner representa uma contribuição importante e original ao acervo teórico da sociologia do direito. A teoria sistêmica propõe um sofisticado modelo que consegue, com rara competência, identificar movimentos especiais resultantes das fricções entre os subsistemas sociais: político, econômico e jurídico. A idéia da autonomia autopoiética do direito, despida de seus elementos mais biológicos, identifica um processo totalmente distinto daqueles observados e analisados exaustivamente pela sociologia tradicional, que enfatizam a influência das variáveis macrossociológicas na constituição do direito. Em vez disso, a teoria sistêmica aponta uma dupla via na interação desses elementos. Em outros termos, é possível afirmar que o sistema jurídico stricto sensu produz realidade social. As possibilidades de aplicação da teoria sistêmica podem ser ampliadas, com efeito, se tomarmos seu acervo conceitual não como traduções de verdades essenciais, mas como recursos interpretativos da linguagem dos fenômenos jurídicos e de sua ação, de como esses fenômenos não apenas reagem aos estímulos externos (das realidades), mas, em seus signos próprios, constituem aquilo que se convencionou como sendo o real.

\section{GUERREIRO RAMOS E O PARADIGMA SISTÊMICO}

$\mathrm{Na}$ concepção autopoiética, concebe-se a indissociabilidade entre ser/fazer/conhecer/falar no processo de modulação constante entre 0 organismo vivo e o meio. Trata-se, portanto, de uma realidade complexa, que apresenta, ao mesmo tempo, situações de autonomia e de conectividade, na medida em que é gerada em um sistema fechado para informações externas e aberto para a troca de energia. Tal forma de pensar, associada à fenomenologia dos seres vivos em geral e dos seres humanos em particular, constitui-se em um meio produtivo por meio do qual é possível responder, no âmbito da ciência, a questões que hoje são entendidas como inadiáveis. O livro em foco - publicado, em 1981, pela Fundação Getúlio Vargas e vertido para o inglês pela Universidade de Toronto, no mesmo ano - transcende sua área disciplinar convencional - a administração - e aventura-se em um novo paradigma científico, ainda em construção, o qual se relaciona ao direito como sistema autopoiético, sobretudo quando se pensa em termos de ecologia política.

Pioneiro da sociologia brasileira, Guerreiro Ramos possuía formação em ciências sociais e em filosofia, com incursões, sobretudo, na psicologia, na administração e na ecologia. Nasceu em Santo Amaro (BA) no dia 13 de setembro de 1915 e faleceu em 1982. Em 1942, diplomou-se em ciências pela Faculdade Nacional de Filosofia no Rio de Janeiro. Assessorou o presidente Getúlio Vargas entre 1951 e 1954, atuando, em seguida, como diretor do Departamento de Sociologia do Instituto Superior de Estudos Brasileiros (ISEB), instituição cultural criada em 1955 pelo Ministério de Educação e 
Cultura, durante o governo do presidente Café Filho (1954-1955). Gozando de autonomia administrativa e de plena liberdade de pesquisa, de opinião e de cátedra, o ISEB destinava-se ao estudo, ao ensino e à divulgação das ciências sociais, sendo que seus dados destinavam-se à análise e à compreensão crítica da realidade brasileira e à elaboração de instrumentos teóricos que permitisse o incentivo e a promoção do desenvolvimento nacional. Guerreiro Ramos constitui, assim, um dos núcleos mais importantes de elaboração da ideologia nacional-desenvolvimentista que impregnou todo o sistema político brasileiro no período compreendido entre a morte de Vargas, em 1954, e a queda de João Goulart, em 1964. Essa ideologia foi formulada principalmente por Guerreiro Ramos, Hélio Jaguaribe, Cândido Mendes de Almeida, Álvaro Vieira Pinto, Roland Corbisier e Nélson Werneck Sodré.

Além disso, Guerreiro Ramos lecionou na Universidade Federal de Santa Catarina (UFSC), em instituições de ensino superior dos Estados Unidos (Universidade da Califórnia do Sul, Yale University e Wesleyan University), tendo tido, também, uma breve experiência político-parlamentar. Publicou vários livros ${ }^{2}$, inúmeros artigos e ensaios científicos, muitos dos quais foram editados em inglês, francês, espanhol ou japonês.

Guerreiro Ramos encontra-se entre aqueles cientistas que inovaram, com relação à trajetória da ecologia política, da ciência política ou das ciências sociais, de um modo geral. (BOEIRA, 1998). Trata-se, no seu caso, de uma original reorganização paradigmática, uma vez que sua produção científica contribuiu, em muito, para a travessia transdisciplinar e sistêmica entre ciências naturais, humanas e sociais. Na verdade, essa contribuição já podia ser percebida no ensaio que publicou em 1946, na Revista do Serviço Público, acerca da teoria de Max Weber ${ }^{3}$.

O propósito de Guerreiro Ramos, a curto prazo, era conciliar um trabalho acadêmico, intelectual, à ação política junto a núcleos de empoderamento. Assim, nos anos 1930, ele transferiu-se da Bahia para o Rio de Janeiro, onde tentou, sem sucesso, obter uma vaga de professor pesquisador na universidade. Nessa época, vinculou-se ao movimento integralista, por um breve período; foi funcionário do Departamento Administrativo do Serviço Público (DASP) e, depois da II Guerra, incorporou-se à Escola Brasileira de Administração Pública (EBAP) da Fundação Getúlio Vargas. Quando de sua criação, a EBAP pretendia ser a grande escola de formação de quadros de alto nível para a administração pública brasileira, mas nunca chegou a se transformar, de fato, em um centro de pesquisas e estudos. No início dos anos 1950, Guerreiro Ramos participou do Instituto Brasileiro de Estudos Sociais e Políticos (IBESP), também conhecido como Grupo de Itatiaia, que editou os Cadernos de nosso tempo e deu origem ao Instituto Superior de Estudos Brasileiros (ISEB). A proposta do ISEB era a de se constituir em uma liderança intelectual e ideológica para o país, da qual decorresse uma posição de liderança política efetiva. Em decorrência disso, Guerreiro Ramos ingressou na política partidária em 1960 (ABREU, 2001), quando se filiou ao Partido Trabalhista Brasileiro (PTB), a cujo diretório nacional pertenceu. Nas eleições de 1962, candidatou-se a deputado federal pelo então Estado da Guanabara, na legenda da Aliança Socialista Trabalhista, formada pelo PTB e pelo Partido Socialista Brasileiro (PSB), obtendo a segunda suplência. Em 1963, publicou 
Mito e verdade da revolução brasileira, onde transcreveu seu manifesto ao PTB da Guanabara, instando que o partido renunciasse "à ideologia marxistaleninista". Ocupou uma cadeira na Câmara dos Deputados de agosto daquele ano a abril de 1964, quando teve seus direitos cassados pelo Ato Institucional no. 1 (9/4/1964). Em seguida, partiu para os EUA, onde foi acolhido na Universidade do Sul da Califórnia, que possui longa tradição de intercâmbio e cooperação com a Escola Brasileira de Administração Pública (EBAP), da Fundação Getúlio Vargas (FGV).

A orientação seguida por Guerreiro Ramos a partir do estudo que daria origem à publicação de $A$ nova ciência das organizações: uma reconceituação da riqueza das nações, em 1981, é muito mais abrangente do que o paradigma vigente até então. Tal orientação foi alcançada, dentre outros fatores, em virtude do amplo esforço teórico empreendido por um conjunto de pesquisadores durante décadas, conforme se pode depreender das obras de Thomas Kuhn (1962), que deu início ao debate acadêmico sobre as revoluções científicas, e de Edgar Morin (1991), que há pelo menos quarenta anos vem tratando do tema.

Essa revolução paradigmática é bem recebida por aqueles que consideram o pensamento cartesiano, bem como a teoria da evolução de Newton, um paradigma redutor, que procede à fragmentação e à substancialização das coisas. Esse procedimento, no plano epistemológico e ontológico, induz à separação entre o sujeito que conhece e o objeto conhecido. Tudo se passa como se o sujeito cognitivo fosse independente de sua própria ação cognitiva. A lógica formal inerente a esse paradigma moderno - com influência de Newton e Descartes - já em meados do século XIX mostrou-se incapaz de dar conta dos fenômenos complexos que se apresentaram aos cientistas. Assim, a revolução que emergiu naquele período no âmbito dos modelos teóricos explicativos, assentada no conceito de autoorganização, foi ocupando espaços no universo das ciências outrora reservados ao paradigma cartesiano. Posteriormente, na metade do século XX, com a Teoria dos Sistemas de Bertalanffy, ficou mais explícita a transição de um paradigma com referência externa para um outro, auto-organizativo. Tal enfoque pautou as discussões das conferências Macy, em Nova York, nas quais um grupo de cientistas, oriundos de diferentes campos do conhecimento, reuniu-se com a finalidade de refletir acerca da unificação da ciência da mente. Nascia, dessa maneira, a cibernética, cujos estudos foram fundamentais para 0 sucesso de um novo paradigma, centrado no processo, e não mais na substância. Mais tarde, já na segunda metade do século XX, os estudos de Ilyia Prigogine fazem uma releitura da II Lei da Termodinâmica, que havia sido elaborada ainda no século XIX e segundo a qual tudo o que existe no universo tenderia para a entropia (morte térmica). Prigogine sugere que nos sistemas longe do equilíbrio - os seres vivos, a sociedade e a linguagem - essa tendência seria revertida pelo princípio da auto-organização ou da interação, que se transformaria em neguentropia. Assim, na interpretação desses fenômenos sistêmicos e auto-organizativos, abandona-se a lógica linear, de causa/efeito, para adotar-se uma lógica circular, com retroações.

Heinz von Foerster, um dos mais brilhantes participantes das conferências Macy, fundou a biocibernética, que possibilita estudar os 
fenômenos biológicos a partir de uma nova matriz cibernética. $O$ processo de vida é por ele concebido como um sistema fechado para a informação e aberto para a energia, no qual se destaca o papel da interação e, naturalmente, o da auto-organização. Na esteira desses estudos, Maturana e Varela constroem uma teoria cibernética - da qual faz parte o conceito de autopoiese -, que concebe o funcionamento do sistema vivo como um circuito fechado de autoprodução, no qual o produtor e o produto configuram-se circularmente. Nesse processo, conhecer e ser são processos inseparáveis. Tal circularidade, segundo os autores, se explica pelo fato de que "todo o fazer é conhecer e todo o conhecer é fazer" (MATURANA; VARELA, 1991, p.13). Com base nessa visão sistêmica da biocibernética, os pesquisadores, ao observarem 0 comportamento humano, apontam para uma inseparabilidade entre ser/fazer/conhecer/falar. Isso quer dizer que o observador pensa sobre o seu pensar, sobre seu processo cognitivo, numa atitude metacognitiva que é potencializadora do ser/conhecer, na medida em que vai capacitando, gradativamente, esse sujeito numa dimensão cada vez mais complexa. Desse modo, tais metodologias de primeira pessoa primam pela incorporação de experiências pessoais à ciência, de uma forma profunda. Ao contemplarem as exigências científicas da coleta de dados, da interpretação, da validação e da busca de padrões, organizam a experiência em torno da qualidade, e não da quantidade.

Esse debate epistemológico contou com a contribuição de Edgar Morin (1991), de acordo com o qual todos os discursos trazem consigo um paradigma que contém os conceitos fundamentais, ou as categorias mestras, da inteligibilidade do sujeito e, ao mesmo tempo, o tipo de relações lógicas de atração/repulsão (conjunção, disjunção, implicação ou outras) existente entre esses conceitos ou categorias. Assim, "os indivíduos conhecem, pensam e agem segundo os paradigmas inscritos culturalmente neles. Os sistemas de idéias são radicalmente organizados em virtude dos paradigmas" (MORIN, 1991, p. 188).

Partindo desse pressuposto, destacam-se, a seguir, alguns tópicos temáticos que evidenciam, em seu conjunto, a presença de traços do paradigma da autopoiese na obra de Guerreiro Ramos intitulada $A$ nova ciência das organizações: uma reconceituação da riqueza das nações. $\mathrm{Na}$ obra, o sociólogo critica, de forma contundente, as sociedades nascidas da Revolução Industrial, no século XVIII. Ele identifica no lluminismo a instituição da razão instrumental que desequilibra a mente humana, ao proceder à valorização unilateral do que é útil exclusivamente ao indivíduo, e dos pressupostos mecanicistas que separam corpo e mente, concebendo 0 Universo como uma imensa máquina. A racionalidade instrumental, para ele, consolidou-se pendendo em favor do cálculo e do utilitarismo, a partir dos séculos XVII e XVIII. Guerreiro Ramos identifica Hobbes, Bacon e Adam Smith como protagonistas da articulação da razão instrumental. Essa tem dominado a teoria da organização, levando-a, segundo o sociólogo, a um sucesso pragmático, porém ingênuo, que tem exercido um impacto desfigurador sobre a vida humana na sociedade. Basicamente, Hobbes define a razão como uma capacidade adquirida por meio de esforço e como uma habilidade para fazer o cálculo utilitário de conseqüências, pretendendo, dessa maneira, despojar a 
razão de qualquer papel normativo no domínio da construção teórica e da vida humana associada.

A forma encontrada pela sociedade centrada no mercado para absorver o conceito de razão foi torná-lo compatível com a estrutura social normativa, utilitária, calculista. Até o século XVII, a razão era predominantemente normativa, mas, em seguida, passou a ser, gradualmente, substituída pela normatividade da história e da estrutura socieconômica. A razão dos indivíduos foi reduzida ao controle dos instintos, à dedução (como desequilíbrio contra a indução) e aos interesses estimulados pela sociedade mercadocêntrica.

Guerreiro Ramos analisa, ainda, os diferentes postulados levantados por Max Weber, por Karl Manheim, pela Escola de Frankfurt e por Eric Voegelin. O sociólogo parece concordar com Max Weber e Karl Manheim na definição possível da racionalidade substantiva, a qual, no entendimento de Manheim, é um ato de pensamento que revela "percepções inteligentes das inter-relações de acontecimentos" (1940, p. 58) numa determinada situação. Guerreiro Ramos assinala que tal racionalidade constitui a base da vida humana ética, responsável. A razão substantiva, assim, não depende de suas expectativas de sucesso. O sociólogo, todavia, demonstra insatisfação diante da falta de sistematização das alternativas levantadas pelos autores que refere. Lança, com isso, um desafio a si mesmo: o de preparar o caminho para aquilo que define como uma "nova ciência das organizações". Desse modo, ele pretende ir além da desmontagem crítica e histórica da razão instrumental, a fim de construir um modelo de cenários sociais com base na razão substantiva.

Marx, segundo Guerreiro Ramos, foi influenciado pelo lluminismo, ao atribuir à história uma racionalidade que somente é passível de realização por seres individuais. Entretanto, o sociólogo toma como referência obras de orientação marxista, particularmente a de Habermas. A certa altura, afirma que, "na perspectiva do lluminismo, o mundo é descrito em fórmulas matemáticas, e o desconhecido perde seu transcendente significado clássico (no sentido dos gregos da Antigüidade), tornando-se alguma coisa relativa às capacidades de cálculos disponíveis" (RAMOS, 1981, p. 9). Em seguida, faz uma síntese de sua posição em relação à teoria de Marx (RAMOS, 1981, p. 9):

\begin{abstract}
Apesar das proclamações 'dialéticas' de Karl Marx, que pretendeu ter despojado o racionalismo do século XVIII de seus traços mecanicistas, seu conceito de razão está profundamente enraizado na tradição do lluminismo, na medida em que ele acreditava que o processo histórico das forças de produção é racional em si mesmo e, portanto, emancipatório. Isso é uma ilusão, afirma a Escola de Frankfurt, e Habermas, em especial, ocupa-se sistematicamente com esta questão.
\end{abstract}

Guerreiro Ramos não possui qualquer ilusão acerca da possibilidade de uma sociedade ideal, sem conflitos, e, por isso, dedicou-se à elaboração de sistemas sociais, sendo a economia apenas um deles. A obra do sociólogo aqui examinada encontra em E. F. Shumacher um referencial para o exame da economia. Guerreiro Ramos critica a supervalorização da dimensão econômica e a expansão totalitária dos valores de mercado. Ao mesmo tempo, defende a economia dual, cooperativista e 0 valor de uso - 0 que implica a 
descentralização e a delimitação do espaço-tempo da vida econômica. A questão central parece ser a preocupação com a regulamentação da economia por intermédio de uma política ecológica, aparecendo a ecologia política como um novo paradigma.

A economia de base industrial - seja ela capitalista ou socialista pressupõe a infinitude dos recursos naturais, o que, conforme Guerreiro Ramos, é um erro central e trágico. Assim, economia dos países industrialmente mais desenvolvidos não poderá continuar servindo de modelo para os outros países, simplesmente porque não haverá recursos naturais em quantidade suficiente. A escassez ecológica é, portanto, uma raiz oculta da inflação, já que não é percebida no interior do paradigma mecanicista. Tendo em vista tais aspectos, o autor assume uma posição favorável à economia dual, isto é, "à coexistência de sistemas de orientação mutuária - nos quais os respectivos membros produzem para si mesmos uma grande parte dos bens e serviços que diretamente consomem - e de sistemas orientados para o lucro, onde os membros são, essencialmente, detentores de empregos" (RAMOS, 1981, p. 188). Soma-se a esse aspecto um outro: "Os sistemas de orientação mutuária e o setor de troca não são reciprocamente excludentes. Devem ambos ser sistematicamente estimulados, por meio de uma eficiente utilização de transferência (de recursos) num só sentido ou em duplo sentido, para benefício da sociedade em geral" (RAMOS, 1981, p. 188).

O sociólogo toma como referência a teoria geral dos sistemas de Bertalanffy ao contestar fortemente os fundamentos da ciência contemporânea, propondo e construindo um novo paradigma, chamado por ele de paraeconômico (ao qual Capra, por sua vez, dá o nome de sistêmico, no mesmo ano em que publica a obra Ponto de mutação). A ciência é compreendida, na obra de Guerreiro Ramos, como uma atividade que exige, sobretudo, equilíbrio entre razão e intuição. Nesses termos, o sociólogo constrói a crítica à teoria organizacional dominante. Em sua opinião, essa teoria deixa, sistematicamente, de distinguir razão substantiva e razão instrumental (não percebendo diferenças entre organização formal e substantiva); não compreende o papel da interação simbólica nas relações interpessoais em geral e apóia-se numa visão mecanomórfica da atividade produtiva do ser humano. Guerreiro Ramos conclui afirmando que toda a ciência que se baseia exclusivamente nesse tipo de visão não passa de um credo. A concepção sistêmica inclui - e até certo ponto dilui - a concepção mecanicista. Trata-se, assim, de uma recontextualização, e não de uma substituição. $O$ mesmo é válido para a relação estabelecida entre razão substantiva e razão instrumental, como se percebe na proposta de ciência feita pelo autor.

Partindo da crítica à teoria da organização, o sociólogo dá início à composição de uma teoria da delimitação dos sistemas sociais - também chamada por ele de modelo multidimensional, em contraposição ao unidimensionalismo da teoria dominante. $O$ ponto central do modelo multidimensional de Guerreiro Ramos é a noção de delimitação organizacional, que envolve: a) a visão de uma sociedade constituída de uma variedade de enclaves (dos quais o mercado é apenas um) e na qual o ser humano empenha-se em tipos nitidamente diferentes, embora verdadeiramente integrativos, de atividades substantivas; b) um sistema de governo social capaz 
de formular e implementar as políticas e decisões distribuitivas requeridas para a promoção do tipo ótimo de transações entre tais enclaves sociais (RAMOS, 1981, p. 140).

Guerreiro Ramos não faz especulações sobre um futuro desejável, mas relaciona seus conceitos delimitativos com experiências concretas de grupos ainda marginalizados nas sociedades centradas no mercado. Há, particularmente na área da saúde, uma série de experiências que combinam fenonomia, economia, isonomia, por exemplo, conceitos esses que formam uma rede que, segundo o autor, representa o início, como ele próprio salienta, de uma nova ciência das organizações. Para que essa ciência se desenvolva, ela não pode dispensar posicionamentos políticos e valorativos (recontextualizações integrativas), embora a relação dialógica entre ciência e política não tenha sido solucionada por meio dos conceitos antes referidos. Isso pressuporia uma revolução paradigmática que ainda está em estado de potência. Quando o cientista leva em conta a sua experiência no processo de investigação, a ciência redimensiona e cria conceitos incessantemente, aproximando-se, sobretudo de forma existencial, pessoal e parcial, da realidade, considerada dinâmica e multifacetada. Justamente por essa dinamicidade e interdependência essencial de todos os fenômenos - físicos, biológicos, psicológicos, sociais e culturais - é que a neutralidade axiológica deixou de ser um horizonte científico.

A ênfase de Guerreiro Ramos sobre a necessidade de normatividade social está calcada numa crítica à síndrome comportamentalista, isto é, à redução da ação humana à incidência dos condicionantes externos. A normatividade concebida pelo autor não é imposta aos indivíduos por critérios instrumentais de convivência social; é, antes, uma possibilidade de convivência entre indivíduos autônomos, com referenciais que transcendem os interesses de caráter simplesmente utilitário. Desse modo, depreende-se que o paradigma social emergente é meta-histórico e ecossocial (cosmológico). Conclui-se, portanto, que isso implica uma profunda reformulação dos valores que contextualizam a ciência, além de uma compreensão muito clara de que as sociedades humanas não só não estão acima da natureza - tal como imaginavam os primeiros industrialistas - como também têm muito a aprender com as fórmulas por meio das quais a natureza exibe sua dinamicidade, inteligência e capacidade de perdurar.

O maior problema detectado por Guerreiro Ramos é o fato de a sociedade não se reconhecer como "miniatura de um cosmos maior, mas como um contrato amplo entre seres humanos. Assim, a conduta humana se conforma a critérios utilitários que, a seu turno, estimulam a fluidez da individualidade. Na verdade, o ser humano moderno é uma fluida criatura calculista, que se comporta, essencialmente, de acordo com regras objetivas de conveniência" (RAMOS, 1981, p. 54). O sociólogo imagina uma sociedade capaz de permanecer, de durar, em vista de sua parcimônia na utilização dos recursos naturais não-renováveis e de sua capacidade de harmonizar e delimitar organizações pequenas, não-expansionistas. Guerreiro Ramos expressa, assim, a consciência de que sua obra é profundamente política e, ao mesmo tempo, científica, ainda que essa relação não seja facilmente compreensível sob a ótica da razão instrumental e do mecanicismo. A 
normatividade, nesses termos, é, sobretudo, a recuperação da autonomia diante do mercado expansionista e a disposição para orientar-se socialmente no sentido da convivência catártica, evolutiva ${ }^{5}$. O conflito é um gerador de stress e tem solução não só por meio da disposição política, mas, principalmente, por intermédio da adequação de técnicas ecológicas de terapia, de meditação, etc.

No livro de Guerreiro Ramos, percebe-se que os cenários sociais capazes de perdurar e contribuir com o desenvolvimento comunitário e individual dos cidadãos têm - necessariamente - tamanhos, tecnologias, espaço e tempo particulares. Verifica-se, assim, na linha de raciocínio do sociólogo, a não-separação entre espaço/tempo, na medida em que ele identifica diversas faces do tempo, tais como o tempo serial, o tempo convivial, o tempo de salto e o tempo errante. Guerreiro Ramos assinala que Soren Kierkegaard e Henri Bergson descreveram, cada qual ao seu modo, um tipo de experiência humana um tanto criativa, que só ocorre quando o indivíduo consegue romper os limites do social. Tal experiência envolve um salto do fechado para 0 aberto, das normas sufocantes, que caracterizam uma era peculiar, para a eternidade, o que equivale a dizer que esse salto configura-se como uma espécie de autodescoberta individual. Assim, em razão do caráter transocial dos saltos existenciais, seu conteúdo só pode ser articulado por intermédio da experiência simbólica.

O sociólogo reconhece que os modelos sociais dos seres humanos são, em geral, categorias de conveniência. Adverte, no entanto, que a conveniência não é a única preocupação do conhecimento organizacional, o qual deve conduzir à sensibilidade para aquilo que, no ser humano, não pode ser reduzido a termos sociais, de modo a impedir a fluidez da psique e sua deformação como simples espécime da episódica vida empresarial. Desse modo, o conhecimento organizacional deve ser capaz de ajudar o indivíduo a manter um sadio equilíbrio entre as exigências de sua condição corporativa e sua vida interior.

\section{CONCLUSÃO}

Constata-se, por fim, que, para Guerreiro Ramos, a mudança social parte de um contato com o cósmico ou com o "eu mais íntimo", considerados, de certa forma, como o contexto do social emergente. Essa emergência, entretanto, requer qualificações, como a interação simbólica e afetiva, que uma multidão ou um grande aglomerado de pessoas torna inviável. Por isso, o sociólogo defende que a socialização é necessária, mas vem acompanhada de inúmeros perigos, e percebe uma tensão constante entre três dimensões - a social, a cósmica e a subjetiva.

Cabe, ainda, salientar que, para Guerreiro Ramos, a reflexão é indissociável da experiência. Por isso, ao refletir sobre a sua experiência, o ser humano está em ação e, portanto, transformando-se com essa experiência/nessa experiência. Somente uma metodologia capaz de dar conta da realidade em trânsito, que incorpora a experiência pessoal numa 
perspectiva disciplinar, poderá responder a este intricado problema: a relação entre conhecimento científico e experiência pessoal. Da mesma maneira, o sociólogo assinala que, para se manter uma certa coerência teórica entre os vários modelos conceituais apresentados com base no novo paradigma - a autopoiese -, é necessário perceber que não existe uma validação externa: as coerências do operar do próprio ser humano, na ação prática, é que irão propiciar a autovalidação da experiência como conhecimento.

\title{
GUERREIRO RAMOS AND THE AUTOPOIESIS:
}

\section{AN ANOUNCEMENT OF THE SYSTEMIC PARADIGM}

\begin{abstract}
The theory of autopoiesis shares with biocibernetics the following principles: a) to think about the thinking; b) to learn how it is learnt; c) to know how it is known. Presenting traces of that new paradigm, it appeared in Brazil, in 1981, the work entitled A new science of organizations, by Guerreiro Ramos, a black sociologist who is one of the leaders of Brazilian intelligence. The book proposes a "re-conceptualization of the wealth of nations" - which, of course, is a criticism of Adam Smith's economic theory - through the organizational assumptions it postulates. Guerreiro Ramos notes, therefore, that science is understood as an activity that requires, above all, balance between reason and intuition. In those terms, proposing a systemic paradigm, the sociologist participates of an intellectual movement that disputes the groundings of modern science and that, in the legal area, finds in the work of Luhmann and Teubner the expression of an accurate systemic view of Law.
\end{abstract}

Keywords: Autopoiesis. Guerreiro Ramos. Law. Luhmann. Systemic paradigm. Teubner.

\section{NOTAS}

Mauro Gaglietti é Professor Visitante do Mestrado em Direito da URI (Santo Ângelo, RS); Professor e Pesquisador do Curso de Direito da Faculdade Meridional - IMED (Passo Fundo, RS); Doutor em História/PUCRS, Mestre em Ciência Política/UFRGS; Coordena a Editora IMED e é autor de artigos científicos, ensaios e livros. E-mail: maurogaglietti@viars.net

1 A obra, de 232 páginas, inclui prefácio da edição brasileira, bibliografia ao final dos capítulos, nota de rodapé, índice analítico e dez capítulos estruturados da seguinte forma: 1) Crítica da razão moderna e sua influência sobre a teoria da organização; 2) No rumo de uma teoria substantiva da vida humana associada; 3) A síndrome comportamentalista; 4) Colocação inapropriada de conceitos e teoria da organização; 5) Política cognitiva: a psicologia da sociedade centrada no mercado; 6) Uma abordagem substantiva da organização; 7) Teoria da delimitação dos sistemas sociais: apresentação de um paradigma; 8) A lei dos requisitos adequados e desenho de sistemas sociais; 9) 
Paraeconomia: paradigma e modelo multicêntrico; 10) Visão geral e perspectivas da nova ciência.

2 Publicou Sociologia industrial (1951), Cartilha brasileira do aprendiz de sociologia (1955), Introdução crítica à sociologia brasileira (1957), Condições sociais do poder nacional (1957), O problema nacional do Brasil (1960), A crise do poder no Brasil (1961), Mito e realidade da revolução brasileira (1963), A redução sociológica (1964), A nova ciência das organizações (1981) e Administração e estratégias do desenvolvimento (1981).

3 Schwartzman assinala que a obra principal de Weber - Economia e sociedade - foi traduzida para o espanhol por José Medina Echevarria, espanhol refugiado no México e membro do grupo que formou o Colégio de México, muito antes que houvesse traduções equivalentes para o inglês ou o francês. Em 1946, Ramos, trabalhando no DASP, já havia lido e escrito sobre essa obra clássica, enquanto na França e nos EUA ela ainda levaria muitos anos para ela ser lida e entendida mais profundamente. SCHWARTZMAN, Simon. Contribuição de Guerreiro Ramos para a sociologia brasileira. Revista de Administração Pública, Rio de Janeiro, 17, 2, p. 30-34, abril-junho, 1983.

4 Em 1955, Guerreiro Ramos foi conferencista visitante da Universidade de Paris; membro da delegação do Brasil junto à ONU e pronunciou conferências em Pequim, Belgrado e na Academia de Ciências da União Soviética (URSS). Na década de 1970, foi visiting fellow da Yale University e professor visitante da Wesleyan University.

5 Em obras escritas bem antes de A nova ciência das organizações este aspecto é enfatizado, conforme mostra a análise realizada por OLIVEIRA, Lúcia Lippi. A sociologia do Guerreiro. Rio de Janeiro, UFRJ, 1995.

\section{REFERÊNCIAS}

ABREU, Alzira Alves de.. [et al.]. Dicionário histórico-biográfico brasileiro pós-1930. Rio de Janeiro: FGV; CPDOC, 2001.

BOEIRA, S. L. Crise civilizatória e ambientalismo transetorial. Revista de Ciências Humanas, CFH, Universidade Federal de Santa Catarina, Florianópolis, v. 16, n. 23, p. 71-102, 1998.

BOUCOCK, Cary. In the grip of freedom: law and modernity in Max Weber. Toronto:

University of Toronto Press, 2000.

CAPRA, F. O ponto de mutação: a ciência, a sociedade e a cultura emergentes. São Paulo: Cultrix, 1982.

CLASTRES, Pierre. A sociedade contra o Estado. Rio de Janeiro: Francisco Alves, 1988.

FREUND, Julien. Sociologia de Max Weber. Rio de Janeiro: Forense Universitária, 1987.

HABERMAS, Jurgen. Direito e democracia. Rio de Janeiro: Tempo Brasileiro, v. I e II, 1997.

HUSSERL, Edmund. Ideas relativas a una fenomenología pura y una filosofia fenomenológica. México: Fondo de Cultura Econômica, 1996.

KUHN, Thomas. The structure of scientific revolutions. Chicago: University of Chicago Press, 1962.

LEMPERT, Richard. The Autonomy of Law: Two Visions Compared. In: TEUBNER,

Gunther (ed.). Autopoietic law: a new approach to law and society. Berlim/Nova York,

Walter de Gruyter. A perspectiva sistêmica na sociologia do direito: Luhmann e Teubner, pp. 351-373; 372 Tempo Social, Revista de Sociologia da USP, v. 18, n. 1, 1988.

LUHMANN, Niklas. Sociologia do direito. Rio de Janeiro: Edições Tempo Brasileiro, v. I e II, 1983.

"The self-reproduction of law and its limits". In: TEUBNER, Gunther (ed.). Dilemmas of $\overline{l a w}$ in the Welfare State. Berlim/Nova York, Walter de Gruyter, 1986.

"The unity of legal sistem". In: TEUBNER, Gunther (ed.). Autopoietic law: a new approach to law and society. Berlim/Nova York, Walter de Gruyter, 1988. 
Social systems. Stanford, California, Stanford University Press, 1995.

Teoría política en el estado de bienestar. Madrid, Alianza Editorial, 2001.

MANNHEIM, Karl. Man and society in age of reconstruction. New York: Harcourt Brace \& World, Inc., 1940.

MARTINS, Maurício V. É o direito um sistema autopoiético? Discutindo uma objeção oriunda do marxismo. In: MELLO, Marcelo P. (org.). Justiça e sociedade: temas e perspectivas. São Paulo, LTr., 2001.

MATURANA, H. Cognição, ciência e vida cotidiana. Belo Horizonte: UFMG, 2001.

MATURANA, H. ; VARELA, F. El árbol del conocimiento. Santiago: Hachette, 1991.

MATURANA, Humberto. Cognição, ciência e vida cotidiana. Belo Horizonte: Editora

da UFMG, 2001.

MATURANA, Humberto \& VARELA, Francisco J. Autopoiesis and cognition. Boston:

Reidel, 1980.

MELLO, Marcelo P. Welfare State: crise do sistema, crise do paradigma e perspectivas pós-industriais. Archétypon, 4 (10), Rio de Janeiro, 1995.

(org.). Justiça e sociedade: temas e perspectivas. São Paulo, LTr, 2001.

MORIN, Edgar. O método. v.IV. As idéias: sua natureza, vida, habitat e organização. Lisboa: Publicações Europa-América, 1991.

NELKEN, David. Changing paradigms in the sociology of law. In: TEUBNER, Gunther (ed.). Autopoietic law: a new approach to law and society. Berlim/Nova York, Walter de Gruyter, 1988.

NELKEN, David \& FEEST, Johannes (eds.). Adapting legal cultures. Oxford/Portland, Oregon, Hart Publishing. Brunswick, New Jersey, Transaction Publishers, 2001.

NEVES, Marcelo da Costa Pinto. A constitucionalização simbólica. São Paulo: Editora Acadêmica, 1994.

OLIVEIRA, Lúcia Lippi. A sociologia do Guerreiro. Rio de Janeiro: UFRJ, 1995.

RAMOS, Alberto Guerreiro. A nova ciência das organizações: uma nova reconceituação da riqueza nas nações. Rio de Janeiro: FGV, 1981.

SCHWARTZMAN, Simon. Contribuição de Guerreiro Ramos para a sociologia brasileira, In.: Revista de Administração Pública (Rio de Janeiro) 17, 2, abril-junho, 1983, p. 30-34.

SCHUMACHER, E.F. O negócio é ser pequeno. Rio de Janeiro: Zahar Editores, 1983.

TEUBNER, Gunther. Dilemmas of law in the Welfare State. Berlim/Nova York: Walter de Gruyter, 1986.

(ed.). Autopoietic law: a new approach to law and society. Berlim/Nova

York: Walter de Gruyter, 1988.

O direito como sistema autopoiético. Lisboa: Fundação Calouste Gulbenkian, 1989. 1996.

Droit et réflexivité : l'auto-référence en droit et dans l'organisation. Belgique, Bruyland,

TRUBECK, David. Max Weber on law and the rise of capitalism. Wiscosin Law

Review, 3: 720-753, 1972.

WATSON, A. Legal transplants: an approach to comparative law. Edimburg: Scottish

Academic Press, 1974.

WEBER, Max. Economia e sociedade. Brasília: Editora UnB, v. I. 1991

. Economia e sociedade, Brasília: Editora UnB, v. II. 1999. 
Recebido para publicação 11/11/2008

Aceito para publicação 12/01/2009 